\title{
Aplicação de crowdsourcing na gestão e no planejamento de transportes: conceitos, potencialidades e parcerias do Waze
}

\author{
Crowdsourcing application on transportation management and planning: concepts, potential uses and Waze \\ partnerships
}

\author{
Camila Santos Costa $^{1}$ \\ Vivian de Oliveira Fernandes ${ }^{2}$ \\ Mauro José Alixandrini $\mathrm{Jr}^{3}$ \\ 1, 2, 3 Departamento de Engenharia de Transportes e Geodésia, Universidade Federal da Bahia - UFBA. \\ Rua Aristides Novis, 02, Federação. CEP 40210-630. Salvador, BA, Brasil. \\ camilascosta@gmail.com, vivian.fernandes@ufba.br, mauro.alixandrini@ufba.br
}

Artigo - Submissão: 23/06/2015 - Aceito em: 14/12/2015

\begin{abstract}
RESUMO - Este artigo apresenta um levantamento bibliográfico comentado sobre a aplicação do crowdsourcing na gestão e no planejamento urbano, mais especificamente em transportes e mobilidade urbana. Inicialmente, apresenta-se os conceitos de neocartografia e crowdsourcing, e então, a técnica derivada desses, o mapeamento colaborativo. Para ilustrar listam-se exemplos de plataformas colaborativas que utilizam dados espaciais para geração de mapas sobre diversos temas e com diferentes objetivos e públicos-alvo. De forma mais detalhada, apresentam-se os princípios de funcionamento do aplicativo Waze e seu programa de parceria com o poder público em diversas cidades do mundo. Em seguida, descreve-se as contribuições já observadas desses sistemas geocolaborativos para a gestão de cidades, bem como as potencialidades percebidas dadas as ferramentas de que dispõem com ênfase nas questões relacionadas aos sistemas de transportes. Por fim, conclui-se que o mapeamento colaborativo representa um avanço na ciência da cartografia, podendo ser utilizado pelo poder público como ferramenta para democratização dos processos de gestão e planejamento urbano. Sem negligenciar o uso dos formatos tradicionais de coleta de informações, as autoridades podem ser subsidiadas complementarmente por esses dados espaciais gerados colaborativamente para tomada de decisões em perspectiva mais ampla e consistente no âmbito de transportes, assim como de outros setores.
\end{abstract}

Palavras-chave: Planejamento urbano; Mobilidade urbana; Mapas colaborativos, Neocartografia.

\begin{abstract}
This article develops a commented literature research on the use of crowdsourcing tools in urban management and planning, specifically in transports and urban mobility. Initially, we present the concepts of mapping and crowdsourcing, and then the technique of collaborative mapping, derived from those two concepts. In order to illustrate this technique, a few examples of collaborative platforms that make use of spatial data to create maps on different subjects and for different purposes and audiences are listed. In a deeper approach, we present the operating principles of Waze app and its partnership program with local governments in several cities worldwide. Next, we describe how these geocollaborative systems have already contributed for cities management as well as their potential uses, given the tools at their disposal, with emphasis on issues related to transportation systems. Finally, we conclude that collaborative mapping represents a step forward in cartography and can be used by public authorities as a tool for democratization of urban management and planning processes. Without neglecting the use of traditional information collection techniques, they may additionally use these collaborative spatial data for decision-making in a wider and more consistent perspective in transports, as well as in other fields.
\end{abstract}

Keywords: Urban planning, Urban mobility, Collaborative maps, Neocartography.

\section{INTRODUÇÃO}

Para pesquisar aplicações crowdsourcing, é necessário estudar a sua expressiva ligação com a neocartografia. Após abordagem ampla desses dois conceitos, será possível entender os princípios da técnica de mapeamento colaborativo e volunteered geographic information (VGI), que se configuram em aplicações mais frequentes do mobile crowdsourcing, e então apontar as potencialidades de uso desta técnica na gestão das cidades e, mais especificamente, no planejamento de transportes.

Ressalta-se a importância desta temática nos dias de hoje diante da acelerada evolução tecnológica nos campos digitais e dos benefícios e potencialidades que a aplicação desses avanços no âmbito da cartografia tem demonstrado para resolução de alguns dos desafios enfrentados nos processos de planejamento e gestão das cidades. 


\subsection{Cartografia e neocartografia}

As definições de cartografia remetem-se sobretudo à ciência de estudo e elaboração de mapas. Em realidade, cabe observar que qualquer mapa da forma como é construído retrata mais do que aspectos geográficos; revela a visão de quem o elaborou sobre o mundo, ainda que ao representar uma porção dele. Como observa Sousa (2012, p. 39), "todo mapa apresenta uma fala indireta daquilo que sabemos, desejamos saber ou intentamos comunicar". Seguindo esse raciocínio, um mapa deve ser interpretado levando-se em conta, além das informações espaciais contidas nele, a época em que foi elaborado, seus autores, seus objetivos e os contextos políticos, econômicos, sociais e culturais em que estavam inseridos.

Se por um lado os aspectos culturais influenciam a cartografia e, inevitavelmente, são traduzidos nos mapas, por outro, a própria produção cartográfica exerce influência sobre a sociedade, transmitindo-lhe conceitos ideológicos. O eurocentrismo presente ainda hoje em grande parte das representações cartográficas difundidas em todo o mundo é um exemplo disto.

Ao estudar a história da cartografia no mundo Ocidental, é possível constatar a evolução dos propósitos gerais que envolveram a cartografia ao longo do tempo. Até o século $\mathrm{XV}$, o exercício da cartografia tinha forte caráter de documentação histórica, com foco em relatar as experiências vividas, passadas, nos espaços representados. Entre os séculos XVI e XVII, os mapas passaram a ter atribuição mais funcional, com o objetivo, sobretudo, de demarcação de territórios. A partir de então, o mapeamento foi utilizado para reconhecimento de espaços, inclusive de sua topografia, visando ao desbravamento de novas terras. Já no século XX, Sousa (2012, p. 43) observa que "a cartografia se alia à estatística de modo a mapear e tecer relações entre fenômenos e sua espacialidade". Desta forma, os sistemas de governo passaram a fazer uso da cartografia para estudar aspectos da sociedade ao mapear dados da economia, da segurança pública, da saúde, da educação, dentre outros (SOUSA, 2012).

Ainda no século XX, a difusão do ambiente digital afetou a cartografia e a relação da sociedade com essa ciência por meio do surgimento dos mapas digitais compostos tanto por informações espaciais (pontos, linhas, polígonos) como tabulares (parâmetros incluídos segundo objetivos do mapa, tais como nome de logradouro, velocidade da via etc.) (LIMA et al., 2010).

A produção de mapas digitais, nesse processo, devido às suas facilidades de construção, edição e armazenamento, apontadas por Lima et al. (2010), terminou por viabilizar a popularização do acesso a informações geográficas mais atuais e fidedignas.

No entanto, o potencial de uso de mapas digitais pelo poder público visando ao atendimento às demandas da população, assim como pelos setores econômico e científico, é limitado onde a falta de dados impede o desenvolvimento de análises baseadas em tecnologia geográfica, causando prejuízos ao desenvolvimento do bem-estar social, às cadeias produtivas e ao avanço científico (LIMA et al., 2010).

Freitas (2014), havendo destacado que, para cada avanço da cartografia na história, houve uma evolução correspondente quanto à tecnologia que pôde ser empregada com o fim de mapear - desde pigmentos rudimentares em formações rochosas, passando por bússolas, teodolitos, aeronaves, câmeras fotográficas e o sistema de posicionamento global (GPS, sigla em inglês para Global Positioning System, mais recentemente adotado o termo GNSS, sigla em inglês para Global Navigation Satelite System para se referir a todos os sistemas e não somente ao GPS americano), dentre outros atribui à Internet, sua popularização e às novas formas como os usuários têm participado na geração de conteúdo digital ao mais recente passo desta ciência. Turner (2013 apud Freitas, 2014) denomina esta nova fase de "cartografia da Internet social", ou "neocartografia", referenciando-se a esta nova relação entre a cartografia e os usuários da Internet, que possuem à disposição, hoje, variadas opções de dispositivos digitais, móveis ou não, que lhes permitem, além de acessar facilmente dados, contribuir para a própria produção cartográfica.

Deste modo, uma alternativa diante da dificuldade na coleta e manutenção de dados espaciais é vislumbrada com o crescimento da chamada web 2.0, fenômeno que alterou a relação entre os usuários e os conteúdos disponíveis na rede, alcançou o domínio da cartografia e será detalhado nas seções seguintes.

\subsection{Crowdsourcing}

O termo crowdsourcing está relacionado com o "aparecimento de sites que se utilizam da audiência/multidão (crowd) como fonte (source) de conteúdo ou mão de obra atuante e decisiva para a existência do mesmo" (SOUSA, 2012, p. 76).

$\mathrm{O}$ fenômeno do crowdcourcing tem origens na chamada web 2.0, termo surgido em 2004 para "designar a passagem da web de um meio de consumo para uma plataforma de produção" (SOUSA, 2012, p. 64). Naquele início dos anos 2000, a relação de mão-única até então predominante na rede - informação sempre fornecida pela página para o público, resumindo o acesso à web somente para obtenção de informação -, cedeu espaço a sites cujos conteúdos eram gerados por seus próprios visitantes. A transição de uma web 1.0 para esta então inédita web 2.0 refere-se, portanto, à inovação no modo como a Internet passou a ser utilizada pelo público civil em geral, que deixou de ser composto exclusivamente por "usuáriosconsumidores" para se desenvolver em "usuáriosprodutores" de conteúdo (GOODCHILD, 2007 e SOUSA, 2012).

Tendo em vista que qualquer indivíduo pode inserir informações nessas plataformas colaborativas, cabe salientar que o ambiente da web 2.0 pauta-se na premissa da "boa-fé" dos usuários. Desta forma, os dados fornecidos são, a priori, considerados verdadeiros, ainda que os diversos programas que utilizam esta técnica possam ter seus próprios mecanismos de controle e 
validação a fim de aumentar a segurança dos dados (SOUSA, 2012).

Doan, Ramakrishnan e Halevy (2011) julgam importante essa etapa de validação dos dados, dentro de uma lista de cuidados que as plataformas colaborativas devem observar visando à manutenção de dados confiáveis e atualizados nos sistemas, relacionados à atração e fidelização de usuários; à avaliação de suas capacidades; e, finalmente, à depuração e compilação das informações coletadas.

Com relação ao primeiro aspecto, referente à atração e fidelização dos usuários, é evidente que a preocupação inicial se deve ao fato de que a coleta de dados depende da existência de usuários que os forneçam. Complementarmente, Misra et al. (2014) ressaltam que a fidelização da comunidade é importante em decorrência da relevância da análise dos dados em função do tempo. Como estratégias para atendimento a esses itens, pode-se citar ações publicitárias bem como campanhas de reconhecimento, materiais ou não, pela participação. Doan, Ramakrishnan e Halevy (2011) destacam, dentre outras, táticas que envolvem a atração de voluntários, a oferta de remuneração financeira, assim como a estimulação da competitividade por meio da classificação de usuários segundo suas contribuições.

O cuidado seguinte, de avaliação das capacidades dos usuários, é importante em plataformas nas quais esses necessitem possuir conhecimentos específicos para alimentação de dados no sistema. Em alguns casos, podese restringir o público-alvo de determinada plataforma ou seção desta a um grupo específico, que possa demonstrar as habilidades requeridas, em vez de se assumir a abertura a um público em geral (MISRA et al., 2014).

O último aspecto, relativo à depuração e compilação das informações, preza que as entradas efetuadas pelos colaboradores na plataforma devem ser avaliadas antes de compor a base de dados do sistema, para então retornar aos usuários de forma condensada. Para expurgar dados inúteis ou não confiáveis, ou resolver conflitos, Misra et al. (2014) assim como Doan, Ramakrishnan e Halevy (2011) apontam a adoção de controles manuais, com base em uma escala hierárquica entre os usuários - nos casos que envolvam subjetividades que dependam de apreciação humana -, e/ou automáticos - nos casos em que se possa atribuir critérios objetivos para crivo dos dados.

Sousa (2012, p. 80) cita como exemplo de experiências colaborativas na Internet as páginas denominadas wiki, como Wikipédia, e aponta "como início desse movimento, [...] sites como Slashdot e blogs surgidos na virada do milênio XX para o XXI (sic)". Sousa (2012) ainda cita, dentre outros, portais de jornalismo cidadão, sites de compartilhamento de mídias e jogos virtuais, fóruns, programas de mensagem instantânea e redes sociais.

Observa-se ainda que o êxito dessas comunidades colaborativas foi possível graças ao rápido avanço tecnológico, com uma crescente disponibilidade de conexão a Internet, cada vez mais veloz (GOODCHILD, 2007). Além disso, o desenvolvimento e a popularização ainda mais recentes no século XXI de dispositivos como smartphones e tablets representam um fator facilitador para a participação dos indivíduos em ambientes colaborativos, dada a sua portabilidade. A possibilidade de uso desses dispositivos com conexão online em praticamente todos os lugares dentro das áreas de cobertura da rede permite que os sistemas sejam alimentados com dados de maneira mais imediata e, desta forma, respondam de forma mais tempestiva às necessidades dos usuários. As plataformas disponíveis nesses dispositivos, portanto, apresentam vantagem diferencial em relação àquelas limitadas às versões web (SOUSA, 2012).

\subsection{Mapas colaborativos}

A técnica de mapeamento colaborativo corresponde à aplicação do modelo crowdsourcing na área de domínio da cartografia. Esta ideia de "geocolaboração", portanto, refere-se à alimentação de sistemas com dados fornecidos em ambiente digital por seus usuários para geração de mapas. A particularidade, neste caso, se dá devido ao fato de que cada dado inserido em sistemas de mapeamento colaborativo deve ser geolocalizado, ou seja, atribuído a determinada localização (SOUSA, 2012).

Isto significa que os membros das comunidades colaborativas de mapeamento são responsáveis pelo fornecimento de dados que são então alocados em uma base cartográfica em sistemas de camadas sobrepostas, ou aptos até mesmo a criar ou editar o próprio desenho dos contornos viários dos mapas. As plataformas, por sua vez, são capazes de processar esses dados individuais e oferecê-los de volta aos usuários de forma compilada para visualização das informações de maneira espacial.

De forma mais restrita o mapeamento colaborativo relaciona-se com outro termo presente no crowdsourcing o volunteered geographic information (VGI), este último restringe o colaborador a iserção específica de um tema sem a atuação direta sobre feições cartográficas de base. Dessa forma o VGI se referiria a uma sub-classe de crowdcourcing como a do mapeamento colaborativo. Essas iniciativas alteratam muito a cartografia como era conhecida, cuja produção era até então restrita a órgãos oficiais especializados. Viabilizando a participação de indivíduos leigos no processo de criação de mapas, este fenômeno surgiu com potencial, por exemplo, para preencher as lacunas existentes de informações digitais da malha viária de diversas cidades de todo o mundo, sobretudo as de menor porte.

Goodchild (2007) atribui parte do sucesso das plataformas que fazem uso das informações geográficas fornecidas voluntariamente justamente à inteligência dos "sensores humanos" que fornecem dados e formam as comunidades colaborativas. Esta rede de "sensores" é dotada de discernimento, o que representa um diferencial em relação aos sensores estáticos, como radares de velocidade, e até mesmo àqueles móveis, também utilizados por algumas plataformas colaborativas, que registram dados ao serem portados por pessoas, veículos etc. 
Aliado ao desenvolvimento da web 2.0, com seu caráter de funcionamento participativo, e à popularização do acesso à Internet, a ampla disseminação de uso do GPS foi também fundamental para a propagação da técnica de mapeamento colaborativo. A disponibilidade de diversos aparelhos com GPS integrado permite que o público leigo em geral obtenha facilmente suas coordenadas geográficas, ou até mesmo as envie automaticamente às plataformas colaborativas, ao, por exemplo, dirigir com um dispositivo GPS ativado no veículo (GOODCHILD, 2007).

Alternativamente, alguns sistemas podem obter os dados geolocalizados exibindo imagens de satélite ou bases cartográficas digitais nas quais os indivíduos leigos possam identificar uma localização visualmente e então clicar no ponto ou na área de interesse de modo que as coordenadas sejam registradas pelo sistema (GOODCHILD, 2007).

Salienta-se ainda que a "neocartografia" derivada da fusão entre o modelo crowdsourcing e a geografia contribui para a democratização desta disciplina não apenas ao possibilitar que os cidadãos contribuam voluntariamente, de forma inovadora, na produção de mapas, como aponta Goodchild (2007), mas também ao tornar mais fácil e trivial o acesso da população ao conteúdo de mapas digitais.

Cabe, por fim, observar que os diversos programas de geocolaboração funcionam de diferentes formas, uma vez que possuem diferentes propósitos e abrangem diferentes temas nos quais se supõe que o fator de localização seja útil ou pertinente para a análise dos dados. A seguir são relacionadas algumas plataformas que, ao utilizar a técnica de crowdsourcing na produção cartográfica, ilustram o avanço desta neocartografia.

\section{OpenStreetMap $^{1}$}

O OpenStreetMap utiliza a técnica de crowdsourcing para formar uma base cartográfica aberta de todo o mundo, criada e mantida por uma comunidade de colaboradores voluntários. Como é uma plataforma de dados abertos, os mapas resultantes desse trabalho, desde que creditados, são disponibilizados para utilização em interfaces de sites e aplicativos de todo o mundo.

\section{WikiMapia $^{2}$}

O WikiMapia, assim como o OpenStreetMap, constitui-se em uma plataforma crowdsourcing para geração de mapas com dados abertos. A comunidade, além de fornecer dados espaciais, como o desenho do sistema viário ou localização de estabelecimentos e espaços públicos de uma cidade, pode inserir descrições e comentários sobre estabelecimentos, avenidas, bairros e zonas especiais, delimitando suas respectivas poligonais. As informações são alocadas em categorias, de forma a

\footnotetext{
${ }^{1}$ Disponível em: <https://www.openstreetmap.org/about/> Acesso em: 26 abr. 2015.

${ }^{2}$ Disponível em: <http://wikimapia.org/about/> Acesso em:
} 26 abr. 2015. permitir uma melhor estruturação dos dados. À medida que enviam suas contribuições à plataforma, os usuários adquirem novos acessos para edição dos mapas.

\section{HERE $^{3}$}

O aplicativo HERE, desenvolvido pelo grupo Nokia, fornece aos usuários mapas com fotografias em alta definição, inclusive de espaços internos de edifícios públicos, aliados à navegação baseada em GPS. É possível acessar os mapas em modo offline, ou, com conexão de Internet, colaborar com a plataforma compartilhando com os demais usuários dados sobre o trânsito em tempo real, que são utilizados pelo aplicativo para o cálculo de rotas otimizadas. Os usuários podem ainda salvar lugares preferidos e visualizar, de forma integrada, informações e avaliações disponíveis sobre restaurantes, pontos turísticos etc., provenientes de outras comunidades colaborativas como TripAdvisor e LonelyPlanet.

\section{Google Map Maker ${ }^{4}$}

O Google Map Maker é uma ferramenta por meio da qual os usuários podem, de forma colaborativa, editar o Google Maps, base cartográfica mantida pelo Google, de forma a mantê-la atualizada. Os colaboradores podem inserir e editar vias e locais de interesse (estabelecimentos comerciais, praças etc.), bem como revisar as alterações efetuadas por outros usuários. Como forma de controle, as edições propostas por usuários mais novos devem ser aprovadas por usuários mais experientes para serem incorporadas à base do Google Maps.

\section{Mapas Coletivos 5}

O Mapas Coletivos é um aplicativo que permite que qualquer pessoa crie seu próprio mapa colaborativo, sobre qualquer tema. Os usuários podem criar camadas para seu mapa, inserir dados geolocalizados, convidar outras pessoas para montar uma rede de colaboração e editar a privacidade do mapa entre público ou privado. O objetivo dos criadores da plataforma é disponibilizar aos cidadãos "um espaço para reportar questões importantes para a qualidade de vida no espaço público".

\section{Google Maps Engine ${ }^{6}$}

Assim como o Mapas Coletivos, o Google Maps Engine é um recurso que permite que os usuários personalizem seus próprios mapas, a partir da criação de

\footnotetext{
${ }^{3}$ Disponível em: <https://company.here.com/here/> Acesso em: 26 abr. 2015

${ }^{4}$ Disponível em: <http://www.google.com.br/mapmaker/> Acesso em: 26 abr. 2015.

${ }^{5}$ Disponível em: <http://www.mapascoletivos.com.br/about/> Acesso em: 22 mar. 2015.

${ }^{6}$ Disponível em:

<https://support.google.com/mapsengine/?hl=pt-

BR\#topic=1237105> Acesso em: 22 mar. 2015.
} 
camadas sobre a base cartográfica do Google Maps, segundo tema que lhes seja de interesse. É possível então compartilhá-las com outras pessoas que podem visualizar e/ou editar os dados, formando também uma rede de colaboração.

\section{MAPEAMENTO COLABORATIVO E A GESTÃO E O PLANEJAMENTO URBANO}

A participação da sociedade civil em um processo de planejamento urbano ainda se limita, majoritariamente, a consultas efetuadas por meio de formatos tradicionais que exigem a presença física dos cidadãos em determinados eventos, como, por exemplo, audiências públicas. Como um formato relativamente novo, o mapeamento colaborativo, em virtude de suas raízes na técnica de mobile crowdsourcing, configura-se numa alternativa para a democratização da participação popular na gestão das questões urbanas, uma vez que os indivíduos - inclusive minorias, como, por exemplo, uma comunidade de ciclistas - passam a poder participar do processo, a partir de qualquer local, através de um ambiente online (MISRA et al., 2014).

Erickson (2010) revela entusiasmo com a aplicação de modelos geocolaborativos na gestão das cidades devido à noção de que as pessoas tendem a se interessar por programas que se proponham a resolver questões locais, com as quais se identificam seja porque têm queixas a reportar ou conhecimento a compartilhar. À diferença de plataformas crowdsourcing sem relação com aspectos de localização, como as páginas Wiki, esses sistemas contam com a motivação e as informações particulares da região, oferecidas pelos indivíduos que ali vivem.

Nesta perspectiva, além de viabilizar a participação de indivíduos que porventura tenham restrições para comparecer aos eventos presenciais de consulta popular dificuldades referentes às distâncias, aos custos de deslocamento etc. -, o uso de ferramentas colaborativas promove eficiência aos investimentos públicos, transparência dos dados e satisfação dos cidadãos, contribuindo, portanto, com a legitimação por estes das decisões tomadas pelas autoridades (INSUA, 2008 apud MISRA, 2014).

A participação da população, neste formato alternativo, pode se dar de forma indireta por meio do fornecimento de dados - tais como dados de GPS registrando rotas percorridas, velocidade de tráfego, dentre outros - que, compilados, formarão um banco de dados que se tornará objeto de estudo pelo poder público; ou, diretamente, através de feedback sobre os sistemas/ equipamentos urbanos existentes ou apontamento de problemas locais para os quais são demandadas intervenções do poder púbico (MISRA et al., 2014).

A seguir relacionamos alguns exemplos de mapas colaborativos existentes, com diferentes públicos-alvo, temas e objetivos, mas que apresentam pontos em comum: o retrato da vida na cidade e o potencial de uso no planejamento urbano. Alguns deles já possuem parcerias firmadas com os poderes públicos locais, enquanto outros apresentam potencialidades, conforme descrito a seguir.

\subsection{Guia Cultural de Favelas ${ }^{7}$}

O Guia Cultural de Favelas é um projeto formado em parceria entre o poder público e a iniciativa privada, desenvolvido pelo Observatório de Favelas do Rio de Janeiro, que tem como objetivo mapear atividades culturais realizadas nas favelas cariocas. Produtores, artistas, coletivos e outros atores da produção cultural podem inserir dados geolocalizados na plataforma online em diversas modalidades, como artesanato, centros culturais, cinema, circo, dança, fotografia, grafite, música, ponto de encontro, teatro, dentre outros.

O Guia é publicado no site oficial do projeto, onde os cidadãos podem visualizar as práticas culturais mapeadas, colaborando na fomentação e divulgação de projetos nas comunidades.

\subsection{WikiCrimes ${ }^{8}$}

O WikiCrimes é uma plataforma que pode ser acessada tanto em navegador quanto em aplicativo disponibilizado para dispositivos com sistema iOS ou Android, criada com o objetivo de mapear a ocorrência de crimes colaborativamente, permitindo que os cidadãos visualizem a densidade de crimes por região e os tipos de ocorrência registrados. $\mathrm{O}$ site oficial do projeto, no entanto, contém manifestação expressa de que os desenvolvedores não pretendam substituir os órgãos policiais, devendo os cidadãos reportar às autoridades competentes todas as ocorrências inseridas no sistema.

Por outro lado, o aplicativo tenta preencher lacunas quanto ao acesso da população aos dados da criminalidade do Brasil, cumprindo a função social de oferecer transparência sobre os crimes ocorridos, ainda que os dados registrados representem uma amostra. Além disso, a plataforma estimula o envio de denúncias às autoridades competentes, que apresenta uma baixa taxa no Brasil (SOUSA, 2012).

Embora não seja utilizado pelos órgãos oficiais brasileiros na gestão da segurança pública, esse aplicativo, ou a ideia dele, poderia ser incorporado pelo poder público para que, aprimorado, pudesse auxiliar a gestão da segurança pública das cidades e dos estados brasileiros por meio da análise de dados espaciais pelos órgãos competentes.

\subsection{Strava9}

O Strava é um aplicativo baseado em GPS criado para atletas, ciclistas e corredores, que lhes permite

\footnotetext{
${ }^{7}$ Disponível em: <http://guiaculturaldefavelas.org.br/> Acesso em: 22 mar. 2015.

${ }^{8}$ Disponível em:
}

<http://www.wikicrimes.org/main.html;jsessionid=D0B213B 625F62133FBA6296D817F5E60> Acesso em: 22 mar. 2015.

${ }^{9}$ Disponível em: <http://www.strava.com/features > Acesso em: 22 mar. 2015. 
definir metas e registrar seus treinos com dados, dentre outros, de velocidade, rota, data e horário de suas atividades, para posterior análise de desempenho. Além disso, é possível interagir com outros usuários e visualizar as rotas mais populares para cada tipo de exercício em diferentes cidades.

Os dados disponibilizados de modo anônimo também têm sido usados por prefeituras municipais do Canadá, da Inglaterra e da Austrália para gestão do espaço público, como a definição dos trechos mais viáveis e necessários para implantação de novas ciclovias (DEMBO, 2014).

\subsection{RideScout ${ }^{10}$}

O RideScout é um aplicativo gratuito, baseado em GPS, que mostra aos seus usuários, em tempo real, as opções disponíveis de transporte para determinada rota, seja com meios públicos, privados, compartilhados ou até mesmo pedestres. O sistema ainda inclui dados como localização, horários previstos e preços dos serviços (DEMBO, 2014). A plataforma foi desenvolvida nos Estados Unidos e está presente em cidades do país de origem e do Canadá.

O grupo responsável pelo RideScout ainda não tem contratos de colaboração com o poder público, porém já está desenvolvendo um projeto de parceria com municípios e universidades (RIDESCOUT, 2015). Com o banco de dados formado de maneira anônima, o poder público será capaz de visualizar o fluxo de movimento dos cidadãos ao longo do dia e as opções de transporte escolhidas em cada rota, informações que subsidiarão as medidas a serem tomadas visando à melhoria da mobilidade urbana da cidade (DEMBO, 2014).

\subsection{Mapeia DF ${ }^{11}$}

O Mapeia DF é um aplicativo que disponibiliza a seus usuários informações geolocalizadas de pontos e linhas de ônibus existentes no Distrito Federal, com respectivos horários de saída. Os usuários podem visualizar esses dados e participar de forma colaborativa fornecendo em tempo real a localização de um ônibus de determinada linha, bem como o horário em que este de fato passou por determinado ponto.

Segundo o site oficial do projeto, “em breve usuários poderão também qualificar paradas e linhas em critérios como ônibus quebrado, lotado, trafegando em velocidade inadequada e outras inconformidades" (MAPEIADF, 2015). Essas informações podem ajudar o poder público na fiscalização dos serviços e no planejamento do sistema de transporte coletivo local.

\footnotetext{
${ }^{10}$ Disponível em: 〈http://www.ridescoutapp.com/about-us/> Acesso em: 22 mar. 2015.

${ }^{11}$ Disponível em: <http://www.mapeiadf.com.br/> Acesso em: 22 mar. 2015
}

\section{APLICAÇÃO DO WAZE NA GESTÃo E NO PLANEJAMENTO DE TRANSPORTES}

Como observado nos exemplos citados anteriormente, os mapas colaborativos podem ser utilizados pelo poder público para a gestão das cidades e o planejamento urbano, nas esferas, por exemplo, da cultura, segurança pública e mobilidade urbana.

Um aplicativo que já possui um programa de parceria com órgãos governamentais em todo o mundo, e que está inserido no tema da mobilidade urbana e do planejamento de transportes, é o Waze, que será detalhado a seguir.

\subsection{Princípios de funcionamento do Waze}

O Waze é um aplicativo gratuito para smartphones e tablets com sistemas Android, iOS e Windows Phone, dentre outros, que utiliza a técnica de mapeamento colaborativo para navegação baseada em GPS (WAZE, 2015b), criado por desenvolvedores israelense. Em junho de 2013, a empresa foi vendida para o grupo Google (G1, 2013), que, em 2005, havia lançado as ferramentas do Google Earth e Google Maps (SOUSA, 2012).

Em outubro/2014, o Brasil estava entre os cincos países que mais utilizavam o aplicativo, ao lado dos Estados Unidos, França, Reino Unido e México, e entre os 3 principais mercados da empresa, provendo-lhe retorno financeiro por meio da publicidade paga (LESSA, 2014).

De maneira geral, os mapas são criados e editados pelos próprios usuários, que colaboram com o banco de dados virtual do sistema de maneira passiva - ao trafegar com o aplicativo ligado, o dispositivo alimenta o sistema com os dados de GPS, sem necessidade de intervenção manual do usuário durante o uso - e/ou ativa - o usuário pode editar e inserir manualmente informações na plataforma. Isso permite que o aplicativo processe os dados e forneça mapas viários atualizados, com sugestões otimizadas de rota que levam em conta as informações atualizadas sobre o trânsito. Basicamente, o Waze é capaz de mostrar, em tempo real, o que acontece no trânsito, e onde os eventos ocorrem (DATAWAZE, 2014).

\subsubsection{Participação dos usuários}

O Waze apresenta interface amigável que permite que os membros da comunidade editem o traçado geométrico das vias e insiram demais dados geolocalizados nos mapas, de maneira online. $\mathrm{O}$ funcionamento do aplicativo baseia-se no seguinte lema: "Ninguém sabe melhor o que está ocorrendo em uma cidade do que as pessoas que vivem ali” (DATAWAZE, 2014, tradução nossa), ideia que converge com aquela defendida por Erickson (2010) e discutida na seção 2 deste artigo.

Os usuários do Waze podem colaborar passivamente com o sistema ao dirigir com o aplicativo aberto no aparelho móvel com a função GPS ativada, fornecendo, deste modo, dados georreferenciados em tempo real sobre 
fluxo e velocidade de deslocamento nas vias por onde trafegam (WAZE, 2015).

Por outro lado, é possível também contribuir de maneira ativa, atualizando manualmente os mapas quanto ao desenho geométrico, sentido de fluxo e nomes das vias. Além disso, os usuários podem fornecer informações complementares, como: manobras proibidas conforme sinalização de trânsito (por exemplo, proibida curva à direita em determinada interseção); delimitação de estacionamentos inserindo o desenho inclusive de suas vias internas; identificação de pontos de interesse (parques, escolas, hospitais, estabelecimentos comerciais etc.); ocorrência de acidentes ou bloqueios; existência de buracos e perigos; indicação de blitze policiais; localização de radares; preços de combustíveis em postos de gasolina; fotos; dentre outros. A Fig. 1 reproduz uma tela do Waze com indicação de trechos e pontos de congestionamento e bloqueio.

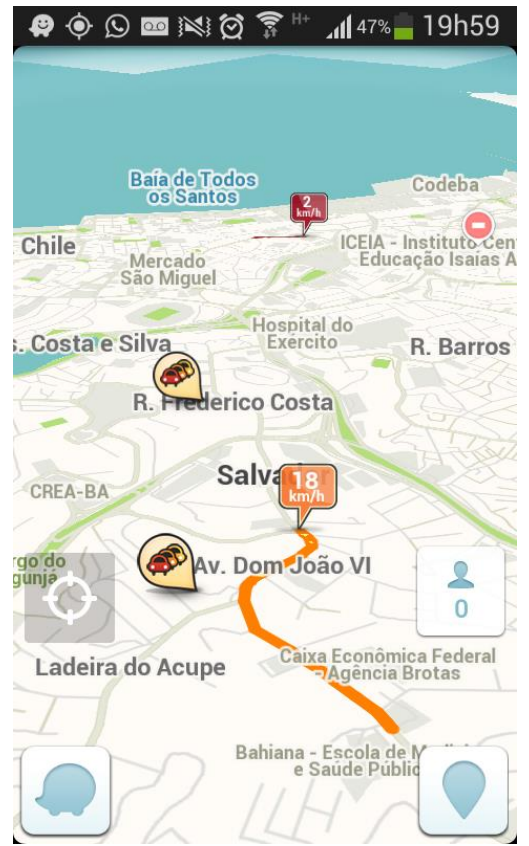

Figura 1 - Congestionamentos e bloqueios exibidos no Waze Fonte: Screenshot do aplicativo Waze em uso (2015).

Os usuários são habilitados a editar e fornecer dados conforme níveis de acesso em que estão enquadrados. Os níveis são atingidos gradualmente à medida que usam e contribuem com o aplicativo (WAZE, 2012), o que lhes atribui pontos. Quanto maior sua pontuação, maiores seu nível de acesso, sua lista de permissões e a influência dos seus dados na plataforma.

Cabe observar que o acúmulo de pontos e a definição de níveis remetem a jogos nos quais o objetivo do jogador é "passar de fase". O estabelecimento de "fases", assim como a divulgação de rankings, a possibilidade de escolher avatares para o perfil de usuário e o oferecimento de pontos extras ao passar por determinados locais da cidade, dão caráter lúdico à plataforma. Outra estratégia adotada para manter os usuários ativos na rede é a possibilidade de visualização e interação com os contatos (tanto da rede social Facebook quanto da própria lista de contatos salva no celular) no ambiente do aplicativo. A interação é possível por meio de trocas de mensagens ou compartilhamento de percursos, conferindo ao próprio Waze também um caráter de rede social. A Fig. 2 ilustra o módulo "Meu Placar" onde o usuário pode visualizar sua pontuação e posição em relação aos demais.

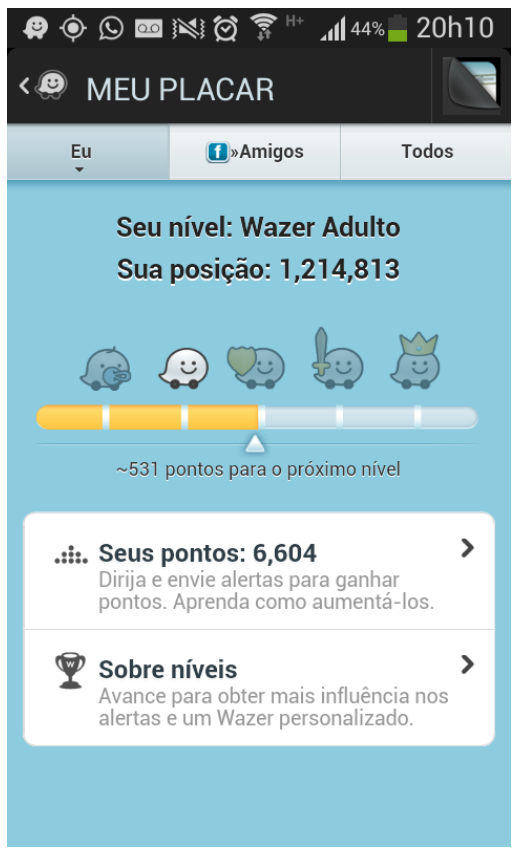

Figura 2 - Exibição de pontuação do Waze

Fonte: Screenshot do aplicativo Waze em uso (2015).

\subsubsection{Criação e edição de mapas}

Para editar os mapas, os usuários devem ser registrados no aplicativo com nome de usuário e senha para acessar a plataforma de edição mostrada na Fig. 3.

Para familiarizar o público leigo em geral com os conceitos de traçado geométrico viário, o editor de mapas trabalha com as seguintes definições para auxiliar a inserção das informações espaciais na plataforma (WAZE, 2012):

(a) Segment - a menor unidade da via, correspondente a um vetor que liga dois pontos de interseção, com direção e sentido definidos;

(b) Junction - ponto de interseção entre dois ou mais segmentos;

(c) End point - ponto final de um segmento no caso de vias sem saída;

(d) Curve points - pontos ao longo de um segmento que permitem ajustar sua forma geométrica. 


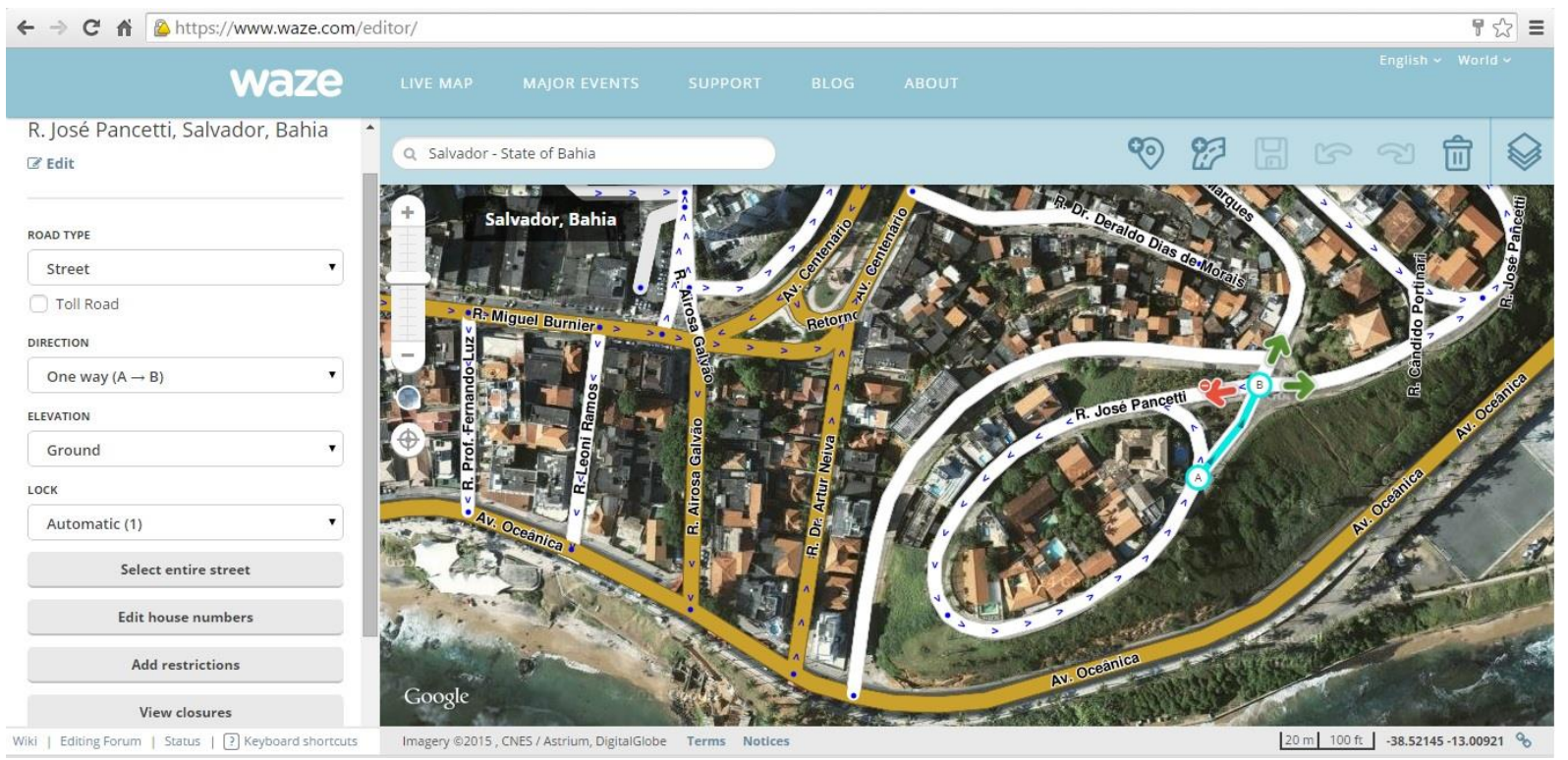

Figura 3 - Editor de mapas do Waze

Fonte: Screenshot (WAZE, 2015a).

As definições acima, assim como outras orientações sobre a edição de mapas, são largamente abordadas em vídeos-treinamento disponibilizados nas páginas oficiais do aplicativo, como estratégia de capacitação de usuários leigos em uma atividade que requer certo conhecimento específico.

Os usuários podem ainda ativar uma camada de imagem por satélite para servir de referência no desenho ou ajuste do traçado das vias. As imagens podem, contudo, estar desatualizadas com as mais recentes modificações efetuadas no sistema viário.

Além da malha viária, os usuários podem inserir informações espaciais com poligonais delimitando pontos de interesse (praças, edifícios comerciais, estacionamentos etc.). As informações tabulares associadas aos diversos elementos espaciais incluem nomes de logradouros e locais de interesse, velocidade máxima das vias, sentido de fluxo, restrições de manobra, fotos, dentre outros. Essas informações formam o conjunto de dados mais "perenes" dos mapas. Embora esses itens possam ser alterados ao longo do tempo, tendem a permanecer válidos durante longos períodos.

Por outro lado, os usuários podem ainda inserir alertas a respeito de situações circunstanciais de maneira geolocalizada nos mapas, como engarrafamentos, blitze policiais, acidentes, perigos, interdições, radares etc., além de dados de preços de combustíveis. Esses dados tendem a ter validade durante curtos períodos, necessitando de atualizações constantes.

\subsubsection{Sistema de camadas}

Os dados inseridos pelos usuários do Waze são armazenados em "camadas" previamente estabelecidas pelo aplicativo de acordo com sua categoria, de modo que cada camada possa ser habilitada ou desabilitada para visualização conforme necessidade do usuário.
Dentre outras, são disponibilizadas as camadas que mostram: outros usuários, trânsito com código de cores conforme níveis de congestionamento, radares, polícia, acidentes, engarrafamentos e perigos.

\subsubsection{Identificação e resolução de inconsistências}

Os dados fornecidos passivamente pelos usuários que trafegam com o Waze aberto e com o GPS do aparelho móvel ligado permitem que o próprio sistema detecte automaticamente, além de pontos de congestionamento, inconsistências no banco de dados (por exemplo, usuários trafegando por um trecho sem via mapeada, andando em fluxo contrário ao indicado ou realizando manobras identificadas como proibidas). Esses tipos de inconsistência também podem ser relatados por usuários, assim como outros problemas que o sistema não detecta automaticamente (por exemplo, o mapa indicando que a entrada à direita é permitida em uma interseção enquanto a sinalização de trânsito indica a manobra como proibida). Tais inconsistências são identificadas no mapa com sinais de advertência para que usuários habilitados as resolvam atualizando o mapa (WAZE, 2012).

\subsubsection{O sistema é vulnerável?}

O fato de utilizar a técnica de mapeamento colaborativo confere vantagens ao Waze em relação aos seus competidores de navegação GPS convencional devido à possibilidade que seus usuários têm de carregar o sistema com dados em tempo real sobre o tráfego nas vias, além de atualizar os mapas assim que são efetuadas alterações no sistema viário (por exemplo, mudança de sentido de fluxo, abertura de novas vias etc.).

O sucesso deste sistema, porém, torna-se dependente da efetiva participação dos usuários, seja passiva ou ativamente. Isto quer dizer que a manutenção da popularidade do aplicativo é essencial para que este continue oferecendo seu diferencial: informações apuradas em tempo real. Diante desse contexto, os contratos de colaboração firmados pelo Waze com o 
poder público e com a mídia, embora não lhe remunerem, lhes são de grande valor ao tender a diminuir essa vulnerabilidade: com os primeiros, garantem o recebimento de informações de mudança de tráfego em primeira mão, e, com os últimos, conseguem divulgar sua marca, sendo promovidos com publicidade positiva. Essas parcerias aliam-se às medidas de estímulo à participação dos usuários discutidas anteriormente (acúmulo de pontos, divulgação de rankings, troca de mensagens entre usuários etc.) como estratégias para atração e fidelização de usuários.

Além desses aspectos, cabe lembrar que o Waze, assim como outras plataformas que usam o modelo de crowdsourcing, como já discutido, baseia-se na premissa de que os usuários, de boa-fé, fornecem dados reais ao sistema. No entanto, visando aumentar a confiança nos dados exibidos no aplicativo, o Waze dispõe de mecanismos próprios de segurança que permitem, por exemplo, que os usuários possam confirmar ou negar as informações fornecidas por outros usuários. Neste caso, prevalece a hierarquia dos níveis de acesso dos usuários, sendo que os dados inseridos pelos usuários com maior pontuação possuem maior influência no sistema.

\subsubsection{Utilidades do aplicativo}

O Waze tornou-se bastante popular em vários países devido às funcionalidades que oferece aos seus usuários finais. Abaixo são descritas as utilidades que o aplicativo oferece ao público em geral:

(a) Mapas atualizados: A inclusão dos dados espaciais em rede contribui para a troca de informações em tempo real, permitindo que o aplicativo forneça aos seus usuários mapas atualizados mesmo com alterações recentes efetuadas no sistema viário.

(b) Filtros por camadas: Além de mapas atualizados, os usuários podem ativar as camadas disponíveis que lhes convier, para visualizar espacialmente informações sobre velocidade de tráfego em cada trecho das vias, blitze policiais, radares, perigos, acidentes etc. Cabe salientar, no entanto, que a divulgação da localização de blitze policiais e radares é controversa, uma vez que os usuários podem usar as informações contidas no aplicativo para fugir desses elementos de controle e burlar as leis, como, por exemplo, evitar passar por uma blitz se estiver dirigindo alcoolizado, ou trafegar dentro dos limites de velocidade permitidos apenas nas proximidades de radares.

(c) Navegação otimizada: Além da exibição de mapas, o aplicativo oferece o serviço de navegação por GPS. Assim como os aparelhos de navegação convencionais baseados em GPS, o Waze sugere rotas ao usuário que informa ponto de partida e destino final, com um diferencial: a sensibilidade em tempo real ao volume de tráfego e a eventos circunstanciais do trânsito, como acidentes ou bloqueios temporários. Desta forma, o aplicativo é capaz de sugerir rotas otimizadas segundo situação do trânsito daquele momento, com base na velocidade de tráfego em tempo real das vias, evitando pontos de congestionamento, conforme ilustra a Fig. 4, em que a rota sugerida evita o cruzamento de um acidente de trânsito informado por um usuário. A interface de navegação ainda permite que o usuário escolha entre evitar pedágios, vias expressas e estradas de terra, fazendo opção por rotas mais curtas ou mais rápidas.

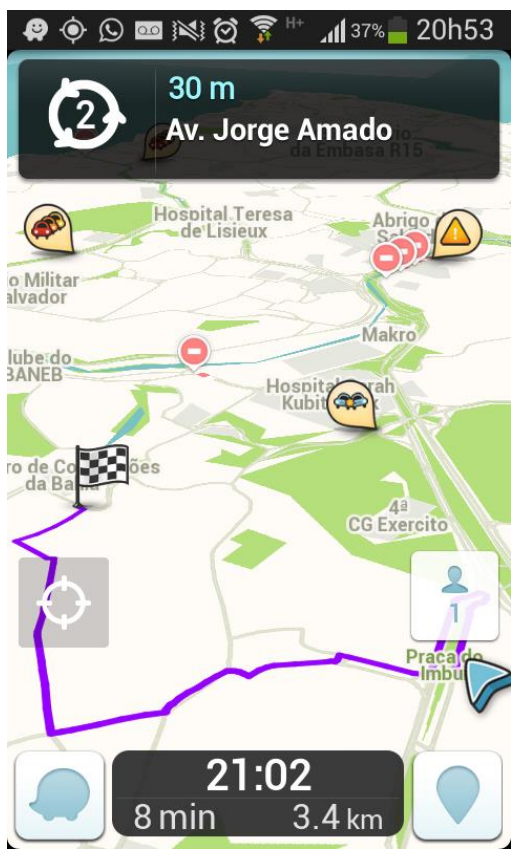

Figura 4 - Sugestão de rota otimizada pelo Waze Fonte: Screenshot do aplicativo Waze em uso (2015).

(d) Dados de preços de combustíveis: Complementarmente, o aplicativo possui a ferramenta que permite que os usuários visualizem espacialmente ou em forma de lista os postos de gasolina com os preços de combustíveis cobrados nestes estabelecimentos. Os dados são atualizados pelos próprios usuários e as datas da coleta de preço são exibidas juntamente com os valores.

(e) Compartilhamento de percurso: Além disso, a conectividade entre membros da rede ainda permite que estes se comuniquem no próprio ambiente do aplicativo e compartilhem seus percursos com outros usuários que façam parte de seus contatos de modo a facilitar a organização de caronas.

Como as informações inseridas pelos usuários no Waze são registradas, de forma anônima, em um banco de dados que "armazena data, horário, velocidade, origem e destino, preferências de navegação e as condições das vias segundo alertas emitidos pelos usuários" (DEMBO, 2014, tradução nossa), os dados gerados pelo aplicativo, por outro lado, também podem ser explorados por órgãos governamentais, com potencialidades de uso no monitoramento das cidades e no planejamento urbano.

\subsection{Programa W10 Cidadãos Conectados}

O Waze já iniciou parceria com órgãos públicos para que utilizem o banco de dados do aplicativo na operação dos seus sistemas de transportes urbanos, por meio do programa intitulado W10 Cidadãos Conectados. O nome do programa faz referência aos 10 primeiros parceiros 
envolvidos no projeto: Rio de Janeiro (Brasil), Barcelona (Espanha), Jacarta (Indonésia), Tel Aviv (Israel), San José (Costa Rica), Estados da Flórida e de Utah (EUA), Boston (EUA), Los Angeles (EUA) e Departamento de Polícia da cidade de Nova York (EUA) (DATAWAZE, 2014).

A primeira cidade a iniciar a cooperação em fase piloto foi o Rio de Janeiro, no Brasil. A parceria entre o aplicativo e o Centro de Operações Rio (COR), órgão responsável pelo monitoramento do cotidiano da capital fluminense, foi uma iniciativa da Prefeitura, que buscava uma ferramenta que lhe pudesse ajudar no recebimento do Papa Francisco na cidade em junho de 2013 (LESSA, 2014). O início bem sucedido motivou o Waze a buscar novos parceiros, expandindo sua rede até culminar com o lançamento do W10 Cidadãos Conectados. Segundo a empresa, o plano é de continuar expandindo o projeto internacionalmente (DATAWAZE, 2014), sendo que mais duas cidades brasileiras, Vitória-ES e Petrópolis-RJ, já assinaram contrato de colaboração, embora não tenham ainda iniciado as atividades de intercâmbio de dados (AGRELA, 2014).

Os contratos de colaboração no âmbito do projeto W10 preveem uma troca "simbiótica", sem remuneração financeira a nenhuma das partes: o Waze envia ao poder público dados em tempo real sobre o trânsito, enquanto os órgãos lhe enviam informações sobre suas ações no trânsito com antecedência, como bloqueios de vias, que são então disponibilizadas nos mapas para os usuários, tornando-os mais apurados e confiáveis (AGRELA, 2014). Os dados enviados pelos usuários do Waze são somados àqueles que os órgãos de trânsito locais porventura já coletem por meio de radares e câmeras de vídeo instalados pela cidade, condensados, e então retransmitidos aos órgãos parceiros (DATAWAZE, 2014).

Desta forma, o poder público tem à sua disposição um panorama mais completo para monitoramento do trânsito, baseado no qual poderá coordenar ações em prol de melhorar o fluxo de veículos, as rotas dos modais de transporte coletivo e a infraestrutura viária da cidade.

Cabe salientar que o estabelecimento de parcerias público-privadas (PPP) com uma plataforma existente e sólida dispensa o poder público de assumir os investimentos necessários em desenvolvimento de software e publicidade, essenciais para que um sistema colaborativo funcione satisfatoriamente. No caso do W10 Cidadãos Conectados, como a relação é não onerosa, a parceria parece ser ainda mais vantajosa ao poder público. Entretanto, resta às instituições governamentais, conforme ressalta Dembo (2014, tradução nossa), "avaliar a validade do método de coleta de dados do aplicativo", procurar assegurar-se do anonimato dos cidadãos que inserem as informações no sistema e levar em consideração que apenas uma parcela dos cidadãos presentes no trânsito são usuários da plataforma.

A necessidade desses cuidados, no entanto, não inviabiliza a utilização de dados coletados em mapas colaborativos pelo poder público.

O COR, no Rio de Janeiro, por exemplo, possui uma Sala de Controle equipada com um telão de $80 \mathrm{~m}^{2}$ onde os dados disponíveis são exibidos de forma integrada para monitoramento da cidade e analisados por mais de 400 funcionários visando ao enfrentamento de situações críticas (PREFEITURA, 2015). Através da parceria com o Waze, esta Sala visualiza espacialmente os dados disponibilizados pelo aplicativo, como os alertas inseridos pelos usuários, integrados com seus próprios meios de monitoramento, tomando, dessa forma, conhecimento em tempo real sobre o que acontece no trânsito e na cidade de maneira geral, inclusive sobre situações como enchentes e deslizamentos de terra. Com base nesses dados, o COR envia os recursos necessários para a normalização da situação (WAZE BRASIL, 2014) ou aciona os órgãos competentes (PREFEITURA, 2015).

Além de aplicações no cotidiano da operação de tráfego da cidade e nos estudos necessários para o planejamento de transportes, a parceria com o Waze permite que o poder público use os mapas colaborativos em situações de emergência ou calamidade pública, como enchentes, terremotos e outros desastres naturais. $\mathrm{O}$ aplicativo, nesses casos, serve como mais um meio de comunicação com a população, seja para envio de alerta para evacuação ou para indicação de locais com abrigo (DATAWAZE, 2014).

Segundo o Waze, as informações fornecidas ao poder público são as mesmas disponíveis no aplicativo, respeitando-se o anonimato dos usuários (DATAWAZE, 2014), que compartilham os dados do trânsito por onde trafegam e funcionam, portanto, praticamente como agentes de trânsito espalhados pela cidade (WAZE BRASIL, 2014).

Com o uso da plataforma e análise do seu banco de dados, portanto, é possível perceber a necessidade de melhorias operacionais ou até mesmo na infraestrutura da cidade. Desta forma, o poder público tem em mãos uma ferramenta que viabiliza:

(a) o monitoramento em tempo real da situação do trânsito, de modo que possa tomar decisões operacionais buscando a melhoria do fluxo de veículos;

(b) a análise de um vasto banco de dados que lhe permite conhecer os hábitos cotidianos dos cidadãos de modo que possa prever os fluxos de movimento e a ocorrência de eventos críticos (acidentes, buracos, deslizamentos de terra etc.) pela cidade visando ao planejamento de transportes, e, de maneira mais ampla, ao próprio planejamento urbano;

(c) a comunicação rápida com a população em caso de emergências.

\subsubsection{Ampliando o escopo}

Em outubro de 2014, ainda foi noticiado por Agrela (2014) que o Waze apresentaria uma nova funcionalidade no aplicativo com uma versão englobando o serviço de táxi. A possibilidade de agregar mais tipos de dados ao aplicativo revela a flexibilidade da plataforma com perspectiva para novas potencialidades.

Imagina-se, por exemplo, que um dia, em um único sistema, seja possível ainda agregar dados referentes ao serviço público de transporte coletivo. Neste caso, os 
usuários finais poderiam visualizar a situação em tempo real do tráfego, exibir as rotas e horários de ônibus e metrôs e solicitar serviço de táxi; e, o poder público, confrontar e analisar os dados para propor e implementar mudanças que otimizem o tráfego e a vida na cidade.

\section{CONSIDERAÇÕES FINAIS}

Se em diversos momentos da história a cartografia foi utilizada para que se pudesse reconhecer obstáculos a fim de vencê-los - sejam inimigos em guerra ou acidentes geográficos, hoje vislumbramos no mapeamento colaborativo uma possibilidade de se estabelecer mais cidadania.

O modelo de colaboração democratiza o processo de mapeamento da vida nas cidades: mesmo minorias eventualmente marginalizadas têm a ferramenta que lhes permite assumir uma parte do papel de atores na produção cartográfica - com a ressalva tratada mais adiante sobre a necessidade de universalização da inclusão digital a toda a população. Esta participação de forma ativa engloba tanto a possibilidade de inserir dados reais que demonstrem as deficiências a que são submetidas em mapas colaborativos existentes, quanto a de criar redes próprias para a produção de um mapa que utilize esta técnica para tratar de um tema que lhes seja de interesse.

O caráter colaborativista dessas plataformas de mapeamento oferece aos cidadãos tanto um instrumento de percepção e iteração do seu entorno, quanto uma ferramenta de transparência de dados relativos às diversas questões urbanas de forma eficiente e "em tempo quase real".

Tão importante quanto esses aspectos é a possibilidade que o próprio poder público tem de adotar e usar essa ferramenta na gestão urbana - o que, felizmente, já tem sido registrado. O uso desses instrumentos pelos órgãos governamentais possibilita, afinal, que a compilação dos dados espaciais coletados de fato resulte em ações efetivas em busca da melhoria do espaço urbano. Com os mapas colaborativos, as autoridades competentes podem analisar dados, planejar e pautar suas decisões com base nos problemas e nas demandas identificadas pelos cidadãos para, finalmente, agir e melhorar as condições para a população.

Pôde-se verificar que já há práticas no sentido de produzir dados espaciais, coletados colaborativamente, nas áreas de cultura, segurança pública e mobilidade urbana, porém é possível ampliar a utilização desse modelo em áreas como educação, economia, saúde, saneamento etc.

No caso do planejamento de transportes, parcerias como a do Waze - aplicativo que usa o mapeamento colaborativo para oferecer navegação baseada em GPS com dados em tempo "quase real" sobre o trânsito - com os órgãos inseridos no programa W10 Cidadãos Conectados disponibilizam ao poder público dados espaciais que permitem a realização de estudos de tráfego e análises do comportamento de deslocamento dos cidadãos ao longo do dia, da semana e do ano e conforme região da cidade e condições do tempo. Além disso, podem permitir a confrontação entre as rotas percorridas pelos cidadãos e àquelas conduzidas pelas linhas existentes do serviço de transporte coletivo, como ônibus e metrô. Esses estudos podem conduzir a propostas de modificações nos sistemas viário e de transporte coletivo, que, quando concretizadas, e aliadas à manutenção das vias por meio da identificação de problemas pontuais como buracos e acidentes durante o acompanhamento operacional, resultem na melhoria da mobilidade urbana da população.

Apesar do Waze não dispor de uma API (Application Programming Interface) o que possibilitaria obter dados de trânsito para trabalhos independentes Jeske (2013) mostra que é possível utilizar aplicações sniffing para obter dados do protocolo Waze. A mineração destes dados amplia o escopo possibilidade de uso, em que o gestor público pode hierarquizar pontos críticos ou mesmo avaliar potenciais da sua malha rodoviária.

Com relação aos cuidados necessários para manutenção de uma base de dados sólida em um sistema colaborativo, verificou-se que o Waze apresenta estratégias relacionadas à atração e fidelização de usuários, como, por exemplo parcerias que promovem a divulgação da marca e sistema de pontuação com publicação de rankings; à capacitação da comunidade para realização das atividades de criação e edição de mapas; e à depuração e compilação dos dados coletados, estabelecendo níveis de acesso hierárquicos em que usuários mais experientes, com maior poder de sensibilização do sistema, podem avaliar as contribuições daqueles mais novatos e resolver inconsistências nos mapas que o sistema detecta automaticamente.

Cabe ressaltar, no entanto, que os dados coletados nesses sistemas colaborativos não se referem, obviamente, à toda a população que deve ser assistida com os serviços públicos, mas a uma amostra desta. Tal amostra, inclusive, tem grandes chances de ser tendenciosa, afinal, o acesso a smartphones, tablets e computadores não é universal. Neste caso, é possível imaginar que as informações coletadas incluam menos dados oriundos, por exemplo, das classes sociais mais baixas, que têm acesso limitado aos dispositivos ou à conexão de Internet em velocidade satisfatória, ou de faixas etárias mais elevadas, como de idosos que possuem menos familiaridade com os recursos tecnológicos mais recentes. Diante disto, fica claro que, embora bastante útil, o poder público não deve se limitar a essa fonte de dados.

Por outro lado, tendo em vista que as plataformas de mapeamento colaborativo viabilizam a participação de certa parte da população nos processos de coleta de dados e demandas, ressalta-se que o poder público não deve tampouco ignorar a ferramenta. Entende-se que se deve, em seu lugar, agregá-la aos métodos convencionais de coleta de dados e consultas à população em processos de gestão e planejamento de transportes, tornando-os cada vez mais participativos e democráticos de modo que conduzam a soluções efetivas das questões de mobilidade urbana de cada localidade. 


\section{REFERÊNCIAS BIBLIOGRÁFICAS}

AGRELA, Lucas. Brasil está entre os cinco países mais populares no Waze. 24 out. 2014. Disponível em: <http://info.abril.com.br/noticias/bitnocarro/2014/1 0/brasil-esta-entre-os-cinco-paises-mais-popularesno-waze.shtml> Acesso em: 15 mar. 2015.

DATAWAZE. Blog oficial do Waze. Introducing the W10 and the new connected citizens platform. 01 out. 2014. Disponível em: <http://datawaze.com/2014/10/01/introducing-the-w10-and-thenew-connected-citizens-platformprogram/> Acesso em: 15 mar. 2015.

DEMBO, Ma'ayan. The power of Public-Private Partnerships: mobile phone apps and municipalities. 25 ago. 2014. Disponível em: <http://www.planetizen.com/node/70934> Acesso em: 15 mar. 2015.

DOAN, Anhai; RAMAKRISHNAN, Raghu; HALEVY, Alon Y. Crowdsourcing systems on the World-Wide Web. Communications of the ACM, v. 54, n. 4, p. 8696, abr. 2011. Disponível em: < http://m.cacm.acm.org/magazines/2011/4/106563crowdsourcing-systems-on-the-world-wideweb/fulltext> Acesso em: 03 maio 2015.

ERICKSON, Thomas. Geocentric crowdsourcing and smarter cities: enabling urban intelligence in cities and regions. UbiComp'10, Copenhague, Dinamarca, 26-29 set. 2010. Disponível em: < http://citeseerx.ist.psu.edu/viewdoc/download?doi= 10.1.1.188.6036\& $\mathrm{rep}=$ rep1\&type $=$ pdf $>$ Acesso em: 03 maio 2015.

FREITAS, Maria Isabel Castreghini de. Da cartografia analógica à neocartografia: nossos mapas nunca mais serão os mesmos? Revista do Departamento de Geografia - USP, Volume Especial Cartogeo, p. 2339, 2014. Disponível em: < http://www.revistas.usp.br/rdg/article/viewFile/855 47/88336> Acesso em: 22 jun. 2015.

G1. Google confirma a compra da Waze. 11 jun. 2013. Disponível

em: <http://g1.globo.com/tecnologia/noticia/2013/06/goo gle-confirma-compra-da-waze.html $>$ Acesso em: 15 mar. 2015.

GOODCHILD, Michael F. Citizens as sensors: the world of volunteered geography. Workshop on Volunteered Geographic Information, Santa Bárbara, Estados Unidos, dez. 2007. Disponível em: <http://www.ncgia.ucsb.edu/projects/vgi/docs/posit ion/Goodchild_VGI2007.pdf $>$ Acesso em: 10 maio 2015.

INSUA, David R. et al. Towards decision support for participatory democracy. ISeB, v. 6, p. 161-191, 2008. apud MISRA, Aditi et al. Crowdsourcing and its application to transportation data collection and management. Transportation Research Record: Journal of the Transportation Research Board of the National Academies, Washington, Estados Unidos, n. 2414 , p. $1-8,2014$.
JESKE, Tobias. Floating Car Data from Smartphones: What Google and Waze Know About You and How Hackers Can Control Traffic. Black Hat Europe: 2013.

LESSA, Izabela. Waze firma parcerias com prefeituras $e$ meios de comunicação brasileiros. 24 out. 2014. Disponível

em: <http://www.proxxima.com.br/home/mobile/2014/1 0/24/Waze-firma-parcerias-com-prefeituras-emeios-de-comunicacao-brasileiros.html > Acesso em: 15 mar. 2015.

LIMA, Renato da Silva et al. Mapeamento colaborativo: uma alternative para a obtenção de mapas digitais para aplicações de transportes. ENGEVISTA, v. 12, n. 1, p. 10-21, jun. 2010.

MAPEIADF. Disponível em: <http://www.mapeiadf.com.br/> Acesso em: 22 mar. 2015.

MISRA, Aditi et al. Crowdsourcing and its application to transportation data collection and management. Transportation Research Record: Journal of the Transportation Research Board of the National Academies, Washington, Estados Unidos, n. 2414, 2014, p. 1-8. Disponível em: <http://ledantec.net/wpcontent/uploads/2014/09/Misra-et-al-2014Crowdsourcing.pdf $>$ Acesso em: 26 abr. 2015.

PREFEITURA do Rio de Janeiro. Página oficial do Centro de Operações Rio. Institucional. Disponível em:

<http://www.centrodeoperacoes.rio.gov.br/instituci onal> Acesso em: 19 mar. 2015.

RIDESCOUT (2015). Disponível em: <https://storage.googleapis.com/ridescoutwebsite.a ppspot.com/media_kit.pdf> Acesso em: 22 mar. 2015.

SOUSA, Paulo Victor Barbosa de. Mapas colaborativos na Internet: um estudo de anotações espaciais dos problemas urbanos. Dissertação (Mestrado) Programa de Pós-Graduação em Comunicação e Cultura Contemporâneas, Universidade Federal da Bahia, Salvador, 2012. 168 p. Disponível em: <https://repositorio.ufba.br/ri/bitstream/ri/5963/1/ Paulo\%20Victor\%20. \%20Mapas\%20Colaborativos\% 20na\% 20Internet. pdf> Acesso em: 15 mar. 2015.

TURNER, A. Neocartography and the social web In: International Cartographic Conference (ICC): From pole to pole, 26th, 2013. Dresden. Proceedings... Dresden: ICA, 2013. p. 53 (\#1218) apud FREITAS, Maria Isabel Castreghini de. Da cartografia analógica à neocartografia: nossos mapas nunca mais serão os mesmos? Revista do Departamento de Geografia USP, Volume Especial Cartogeo, p. 23-39, 2014.

WAZE (2015a). Editor de mapas do Waze. Disponível em: <https://www.waze.com/editor/> Acesso em: 21 jun. 2015.

(2015b). Site oficial do Waze no Brasil. Sobre nós. Disponível em: <https://www.waze.com/ptBR/about> Acesso em: 15 mar. 2015. 
Canal oficial do Waze no YouTube. Waze Map Editor Guide Full Clip | Waze. 30 abr. 2012. Disponível em: <https://www.youtube.com/watch?v=HVksbb1Z4S Q> Acesso em: 15 mar. 2015.

WAZE BRASIL. Canal oficial do Waze Brasil no YouTube. Parceria Waze e COR (Centro de Operações do Rio). 29 ago. 2014. Disponível em: <https://www.youtube.com/watch?v=_hqk1Piu2fs > Acesso em: 15 mar. 2015. 